\section{Are you a leftie or rightie?}

For left-handed dentists the composition of a dental unit and its accompanying modules can be a source of discomfort, if they're

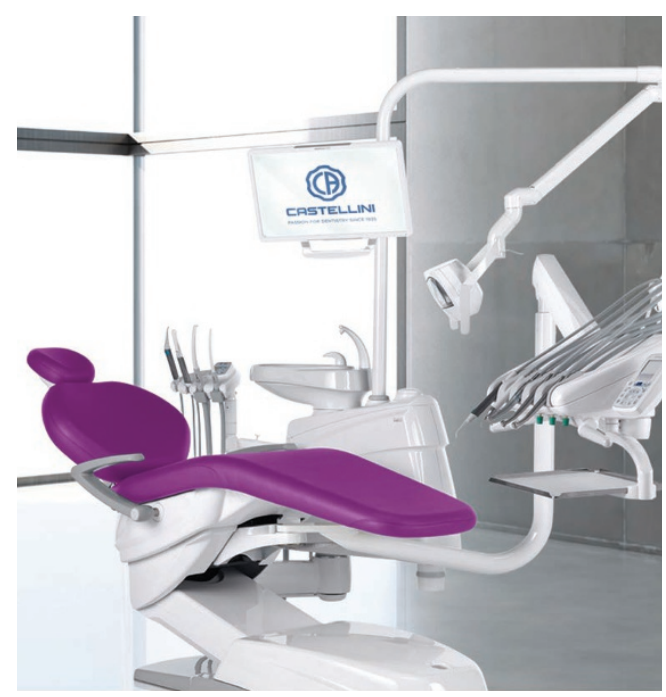

required to twist, turn or reach. Fortunately, there is a solution, and it's called the Castellini Puma ELI Ambidextrous.
Available from RPA Dental, the Puma ELI Ambidextrous allows dentists to change the instrument set-up from right to left making it ideal for both right- and lefthanded users. Best of all, the changeover can be done in just a few minutes with little effort required from the dentist.

Its flexibility, however, doesn't stop there. Designed with optimised vertical excursion, the user is able to adjust the instruments to the most convenient height, with handles on both sides of the dentist's module for ambidextrous use. The result is a complete, multipurpose unit that provides maximum efficiency and comfort for dentists that work both left- and right-handed.

For more information on how you could achieve a flexible workflow, contact RPA Dental about the Puma ELI Ambidextrous.

Visit www.rpadental.net. For the

London and Manchester Sales and Service Centres call 08000933975.

\section{Dental study tours in 2018}

Join Jon Baines Tours Dental Study Tour to Japan from 26 September to 7 October 2018, led by Dr Ashok Sethi. Examine contemporary and historic Japan alongside visits to clinics, a dental school and CPD lectures. From Tokyo, take the bullet train to the samurai town of Kanazawa and on to the manufacturing hub of Nagoya. Visit the Peace Park in Hiroshima and cruise the Inland Sea, experience the cuisine of Osaka and Kobe and explore traditional Japan in Kyoto.

Full details can be found at www. jonbainestours.com/japan.

With the Jon Baines Tours Dental Study Cruise in Russia from 5-16 October 2018, you can combine a cruise along the Volga
River with one night in Moscow and three in St Petersburg. Learn about Russia's rich culture and history, alongside $\mathrm{CPD}$ lectures and specialist visits in Moscow and St Petersburg. The cruise ends with three nights at the luxury Astoria Hotel in St Petersburg. The onboard CPD lectures are complemented by talks by the tour leader, Dr Tony Druttman, on his own fascinating connections with Russia.

The cruise runs alongside a medical history cruise itinerary and participants are welcome to attend these lectures.

Full details are at www.jonbainestours. com/dentalrus. For more information contact Jon Baines Tours on +44 (0)20 72239485 or info@jonbainestours.co.uk.

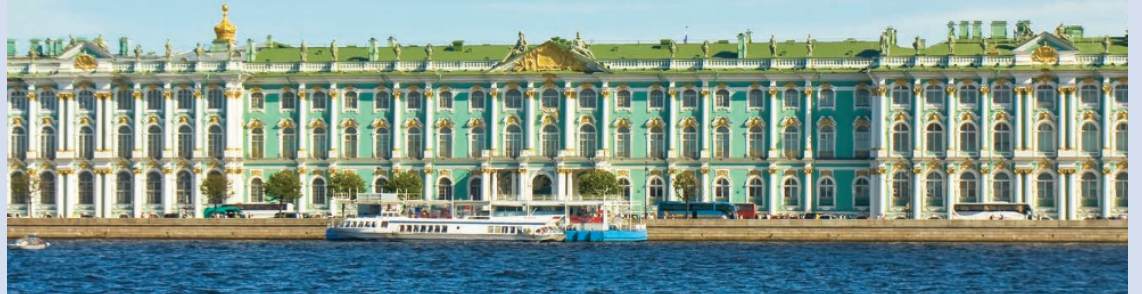

\section{Simplify bonding}

If you need a light-cured, one-component bonding system that can be used with either the self-etching, selective etching or total etch technique, then you should try ONE COAT 7 UNIVERSAL from COLTENE.

Areas of application include:

- Bonding in adhesive restoration techniques

- Adhesive attachment of composite materials and compomers on enamel and dentine

- Adhesive attachment of ceramic and composite restorations on enamel and dentine

- Composite material on ceramic, composite material, metal and amalgam

- Dentine sealing.

The versatile nature of ONE COAT 7 UNIVERSAL, exceptional bonding values

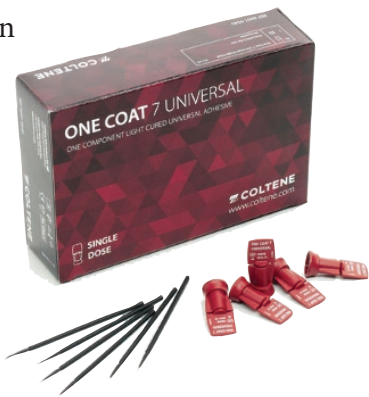
on enamel and dentine and minimised postoperative sensitivity make this COLTENE product a useful all-round bonding agent for any practice. So why not try the ONE COAT 7 UNIVERSAL today?

The one-component bonding system is available in either a convenient bottle that provides up to 300 applications, or as a practical single dose.

To find out more visit www.coltene.com, emailinfo.uk@coltene.com or call 01444 235486 .

\section{Erratum}

Product News, 12 January 2018

The item $A$ state-of-the-art facility dedicated to implant training (BDJ 2018; 224: 55) incorrectly stated that Jonathan Green (GDC Director of Fitness to Practise) was present at the General Dental Council's (GDC's) Fitness to Practise Study Club held on 23 November 2017 at the Implant Centres of Excellence (ICE) Postgraduate Dental Institute \& Hospital in Salford Quays in Greater Manchester.

Jonathan Green was not present at the event and is no longer employed by the GDC.

We apologise for any confusion caused. 